\title{
The EPA/EADS/ESC position statement on diabetes and cardiovascular risk in patients with severe mental disorders
}

Hans-Jurgen Möller

From $1^{\text {st }}$ International Congress on Neurobiology and Clinical Psychopharmacology and European

Psychiatric Association Conference on Treatment Guidance

Thessaloniki, Greece. 19-22 November 2009

People with severe mental illnesses, such as schizophrenia, depression or bipolar disorder, have worse physical health and reduced life expectancy compared to the general population. The excess cardiovascular mortality associated with schizophrenia and bipolar disorder is attributed to an increased risk of the modifiable coronary heart disease risk factors, obesity, smoking, diabetes, hypertension, and dyslipidaemia.

Antipsychotic medication and possibly other psychotropic medication like antidepressants can induce weight gain and further increase the risk of adverse metabolic effects which may result in further increased incidence of cardiovascular disease. Patients have limited access to general healthcare with less opportunity for cardiovascular risk screening and prevention than would be expected in a non-psychiatric population.

The European Psychiatric Association (EPA), supported by the European Association for the Study of Diabetes (EASD) and the European Society of Cardiology (ESC) published this statement aiming to improve the care of patients suffering from severe mental illness. The intention is to initiate co-operation and shared care between the different healthcare professionals and to increase the awareness of psychiatrists caring for

Psychiatric Department, Ludwig-Maximilians University, Munich, Germany patients suffering from severe mental illness to screen and treat increased cardiovascular risk factors and diabetes.

Published: 22 April 2010

doi:10.1186/1744-859X-9-S1-S36

Cite this article as: Möller: The EPA/EADS/ESC position statement on diabetes and cardiovascular risk in patients with severe mental disorders. Annals of General Psychiatry 2010 9(Suppl 1):S36.

Submit your next manuscript to BioMed Central and take full advantage of:

- Convenient online submission

- Thorough peer review

- No space constraints or color figure charges

- Immediate publication on acceptance

- Inclusion in PubMed, CAS, Scopus and Google Scholar

- Research which is freely available for redistribution 